\title{
The "other" Spanish: Methodological issues in the study of speech timing in Chilean Spanish
}

\author{
Isadora Reynolds, Olga Maxwell, Gillian Wigglesworth ${ }^{l}$ \\ ${ }^{1}$ School of Languages and Linguistics, The University of Melbourne, Australia \\ reynoldsiestudent.unimelb.edu.au, omaxwell@uniemlb.edu.au, \\ g.wigglesworth@unimelb.edu.au
}

\begin{abstract}
This paper is a preliminary account of speech rhythm and some phonological properties of Chilean Spanish in spontaneous dialogues. Different dialects of Spanish have been studied using rhythm metrics measuring the durational variability of vocalic and consonantal intervals. There are, however, methodological issues regarding the segmentation of intervals, often overlooked in previous research, such as the criteria for categorising certain segments into the different intervals and the segmentation of different voice qualities. The present study addresses this gap and compares rhythm metrics obtained using two methods of segmentation based on the available literature. The analyses reveal that a strictly 'acoustic' approach to segmentation of intervals results in slightly inflated metrics. Nevertheless, both methods show there is significant durational interval variability in Chilean Spanish, compared to other dialects of Spanish, that may be connected to phonological properties of the variety.
\end{abstract}

Index Terms: speech timing, rhythm metrics, Chilean Spanish

\section{Introduction}

The study of speech timing, the rhythmic properties of a language, has long attracted the attention of researchers. More recent work has shown that the production and perception of speech timing is influenced by suprasegmental features, including duration, intensity, and fundamental frequency $[1,2$, 3], where duration has received the most attention. The phonological and phonotactic characteristics of languages that can affect durational patterns are phonemic vowel length, the presence (or lack thereof) of vowel reduction, and the different implementations of stress correlates [4]. As a result, subsyllabic units may play an important part in determining rhythmic properties [1]. Current approaches to the study of rhythm measure the variability of vocalic and consonantal intervals to describe and classify languages within the spectrum of syllable-, stress, or mora-timed languages relying on rhythm metrics [5]. Though the effectiveness of these metrics has been called into question [6], they still offer some insight into the phonotactic properties of a language. This is especially the case when comparing varieties of a particular language when these are known to differ in terms of their phonological and phonotactic characteristics. For this reason, this paper applies rhythm metrics with the aim of describing the prosodic aspects of Chilean Spanish (CLS), an understudied variety whose idiosyncrasies may affect speech timing.

The metrics employed for the study of rhythm are meant to account for variations based on vowel and consonant interval durations. [7] proposes measures that reflect phonological properties, instantiated at the phonetic/acoustic level: $\% \mathrm{~V}$ (proportion of the utterance composed of vocalic intervals), $\Delta \mathrm{C}$ and $\Delta \mathrm{V}$ (standard deviations of consonant and vowel duration respectively). These should account for syllable structure complexity, where higher values correspond to simpler syllables. The rate normalised measures proposed by [8] (VarcoV and VarcoC) indicate differences in vocalic and consonantal interval durations which are not speech-rate dependent. Analogous to $\% \mathrm{~V}, \Delta \mathrm{C}$, and $\Delta \mathrm{V}$, higher scores would indicate higher variability. Finally, Pairwise Variability Index measures proposed by [5], PVI-V for vowels, PVI-C for consonants, associate rhythm with local interval duration relationships which should reflect how much variability there is between successive consonants and vowels.

Rhythm metrics are not without their shortcomings $[1,3,6$, $9,10]$. Methodology, especially at the level of the materials used, can have a great effect on the results. In [3]'s study, scores were influenced by the elicitation method, task type, as well as the inter-speaker variability. Also, [9] found a significant effect of the syllable structure of the materials on the results for $\% \mathrm{~V}$. Further, [10] showed some variability in scores due to differences in segmentation criteria. Most studies follow the standards in [11] for segmentation, but there are differences in methodology among studies which may have a bearing on the results for Chilean Spanish. One example of this is classifying prevocalic glides $[\mathrm{j}]$ and $[\mathrm{w}]$ as belonging either to the vocalic or consonantal intervals. Most studies place onglides as part of the consonantal interval (see [9, 12, 13, 14]) following [7], while a few have followed [5] and [15] who consider these as part of the vocalic intervals (see $[16,17])$. The anti-hiatic tendency of Spanish [18] favours the creation of diphthongs which are shorter than hiatuses; classifying onglides as consonants could therefore impact the duration of intervals. Another potential issue is the presence of allophonic variants and changes in voice quality. For example, it is often unclear how to classify the intervals with devoiced vowels given that these are acoustically consonants but phonologically vowels [19]. In [5], for example, their approach to segmentation was mainly acoustic, so vowels with no voicing were included in the consonantal intervals. Creaky phonation and breathy vowels can also be present in speech samples, and extreme realisations of creaky voice and the voiceless formant structure of breathy voice can make segments longer [20], which would ultimately affect interval durations and durational variability.

\subsection{Spanish in the Americas}

Spanish has long been considered a canonically syllable-timed language [21] [22], where syllables occur in regular intervals and are of relatively equal length. More recently, it has been said that the impression of Spanish as 'syllable-timed' is due to the prevalence of CV syllables, little or no vowel reduction, no 
vowel length distinction, and less pre-boundary lengthening than other languages [9]. Though there are some studies into the rhythm of Latin American Spanish (LAS) varieties [13] [17], most cross-linguistic work to-date is based on Castilian or peninsular Spanish (PS). Yet, PS and LAS can differ greatly, due to the latter's contact with indigenous languages [23] [24].

The vowel system of Spanish has been described as very stable, with some degree of reduction in unstressed syllables but not as extensive as in English [25]. The few studies carried out on contact varieties reveal that certain dialects of LAS show more extensive vowel reduction [24]. Some Mexican varieties have 'falling vowels', where unstressed vowels (especially in contact with /s/) become reduced, or completely elided [26]. Moreover, whole syllables can be elided in fast speech in words such as 'ta' [ta] for 'está' [es'ta] [23]. Another issue that may affect duration is hiatus resolution in sequential vowels, which can be dealt with in four ways: no change (vowels remain in separate syllables), diphthongisation, monophthongisation (fusion of identical vowels, elision, or coalescence), or the insertion of a consonant $[27,28,32]$. Given the anti-hiatic tendency of LAS, vowel hiatus tends to be resolved rather than maintained. In [27], resolution was three times more prevalent than maintenance, and even more so for high-frequency words. This implies that LAS varieties which favour hiatus resolution could have more variable vocalic intervals considering that diphthongs tend to be shorter than hiatuses.

Most varieties of Spanish are prone to the lenition of consonants [24], prevalent in LAS and PS [30]. The two types of lenition which have received the most attention are: the aspiration of $/ \mathrm{s} /$ and the spirantisation of voiced plosives. slenition has three potential allophones: $[\mathrm{s}],[\mathrm{h}]$, and zero realisation. In situations where $/ \mathrm{s} /$ is elided, speakers may produce compensatory lengthening of the adjacent segment to distinguish between minimal pairs, as in 'pesca' ['pe:ka] vs 'peca' ['peka] [23, 31]. According to [13], s-lenition can lead to changes in vocalic ratio as well as greater consonant interval variation. Lenition of voiced plosive results in the spirantised approximants $/ \beta_{\ni}, \partial, \gamma /$. Realisations of these plosives range from a stop, to close approximation, to a vocalic variant which is almost indistinguishable from neighbouring vocalic segments [31]. Elision is also very common, especially in the case of /d/ in the morpheme '-ado' [24]. The extent of lenition and elision varies greatly among dialects and it even extends to voiceless plosives, which can be realised as spirantised approximants in intervocalic position [30]. The tendency of LAS towards voicing of voiceless plosives could also affect rhythm; [32] found that variations in voiceless/voiced intervals can even distinguish between rhythm classes.

\subsection{Chilean Spanish}

CLS has been impressionistically qualified as 'different' from other varieties, and there might be some evidence to these claims. [33] found that PS and CLS not only differ in the number of phonemes and allophones, but also in a stronger tendency of the latter towards lenition. One striking characteristic of CLS, considering its geography, is that most of the variation is socioeconomic rather than geographic $[34,35]$. Regarding the influence of contact with indigenous languages, [36] demonstrated that the vowel space of CLS is closer to that of Mapudungún than other varieties of Spanish. The vowel space of this language is 'narrower' than PS and has close allophones in unstressed position [37]. The influence of other indigenous languages such as Quechua, Aymara, Kawésqar on
CLS phonology has not been widely studied. Regarding vowel duration, [23] describes a phenomenon whereby vowels become lengthened in contact with palatal consonants, and [38] reports length variations for identical vowels in contact depending on their degree of lexical stress. Little has been mentioned about voice quality or the existence of devoiced vowels, but there is clear evidence of these in the data analysed in this study (see Figure 1). In terms of consonants, [39] studied the degree of s-lenition, where -s morphemes were retained to a higher degree in higher socioeconomic strata, and in [34] the preferred realisation was $[\mathrm{h}]$, with high levels of elision. Voiced plosive lenition and elision are widespread in CLS [32], being found in all social groups to higher or lesser degree.

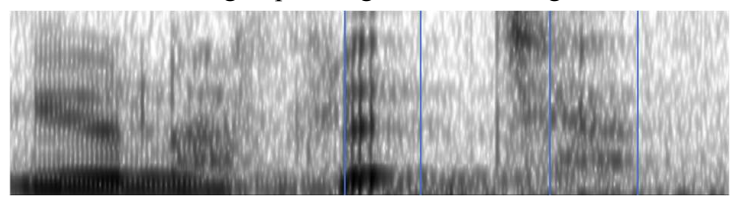

Figure 1: Spectrogram of the phrase 'una flecha' with a creaky [e] and a devoiced [a] between blue lines.

\subsection{The present study}

This paper is an exploratory analysis focusing only on a small subset of the total samples of a larger study. About 16 minutes of spontaneous dialogue recordings were examined, hoping to obtain a preliminary picture of the allophonic changes in CLS and a glimpse at how speech timing is implemented in this variety. The study aims at exploring speech timing in CLS through rhythm metrics. First, it describes what makes this variety 'unique' at a phonological and phonotactic level by looking into hiatus resolution or maintenance in sequential vowels, lenition of consonants, and elision of segments. Then, it investigates whether these features have any influence on the results obtained through rhythm metrics: that is, whether the phonological processes under study contribute to interval duration variability. It should be noted that this paper does not intend to place CLS into any category in terms of rhythm, but rather explore what metrics can reveal about timing in this variety, and how CLS compares to other varieties. The second objective is to examine how different methodological approaches to segmentation could potentially impact the results of the study of speech timing for spontaneous dialogues.

\section{Methodology}

\subsection{Materials}

The materials used for this experiment include the DiapixUK [40], a dialogic problem-solving task that requires speakers to 'spot-the-difference' between two pictures with similar scenes, but with changes in terms of objects or actions.

\subsection{Participants}

Five Chilean females participated of the study. All of them were university students (mean age $=22$ ) recorded in Santiago, Chile in August 2019. This was a subset from a sample of 32 speakers, currently under analysis, and part of a larger study.

\subsection{Segmentation}

While it is known that segmentation is a somewhat artificial endeavour [1], consistency in methodology can help the reliability of this process. This study explores two segmentation 
approaches to see whether they produce similar or different results. Speech samples were force aligned using WebMAUSBasic [41] and then manually corrected in Praat [42] using the standard segmentation criteria in [11], [43], [15], and [5]. In summary, VC boundaries were placed at the end of the pitch period, before a break in the formant structure which includes a dip in sonority. The reverse criteria were used for $\mathrm{CV}$ sequences. Following [5] and [15], pauses were not included in the analysis, pre-pausal syllables were not discarded, dysfluencies and one-word backchannels were pruned out

Subsequently, segments were labelled for lenition, elision, vowel sequences, vowel devoicing, and voice quality changes (breathy/creaky phonation). Sequential vowels were considered as hiatus on the basis of duration and the 'smoothness' of the formant transition between the vowels [44] [45] as well as the presence of two peaks in sonority; they were considered as diphthongs or monophthongs if there was only one sonority peak. Then, F1 and F2 were measured at the 25\%, 50\%, and $75 \%$ mark to determine whether the contact resulted in a diphthong or monophthong [46]. Spirantised approximants were segmented following the guidelines in [32], relying on dips in sonority where there was no evident formant transition; the whole VCV sequence was excluded if there were no cues to allow segmentation. Devoiced vowels, creaky and breathy phonation were identified visually relying on the criteria in [47] and segmented based on auditory and/or acoustic cues.

As the next step, two more tiers were created, one with a 'tight' focus based on acoustic criteria, and the other with a 'lax' auditory-phonological approach

- Method one: on-glides [j] and [w] were classified into the consonantal intervals, vowels were only considered as such if there was a clear formant pattern and on/off-set of voicing, breathy and extreme creaky phonation were not considered as part of the vocalic interval.

- Method two: on-glides [j] and [w] were classified into the vocalic intervals; devoiced, breathy and extreme creaky phonation were considered as part of the vocalic interval.

\subsection{Rhythm metrics}

The following metrics were calculated using the freeware software Correlatore [48]:

- Vocalic: \%V (total duration of vowels divided by duration of the sample); VarcoV (normalised standard deviation of vocalic intervals), nPVI-V (normalised Pairwise Variability Index for vocalic intervals)

- Consonantal: VarcoC (normalised standard deviation of vocalic intervals), rPVI-C (non-normalised Pairwise Variability Index for vocalic intervals)

\section{Results}

Table 1 shows the results for the phonological properties of the samples for each participant. The results for sequential vowels show a high tendency to resolve hiatuses into either diphthongs or monophthongs, which means that speakers make shorter vowel sequences and therefore produce more variability in vocalic intervals. For the realisation of voiced plosives, it can be seen that most of these tokens were realised as spirantised approximants, with some cases of elision. There was also a small percentage of spirantisation for voiced plosives. As can be seen for the average duration of plosives, voiceless plosives were the longest, followed by voiced and spirants. Elision could have also contributed to the variability of interval duration given that this occurred in intervocalic position, favouring the creation of vocalic intervals. Finally, and counter to expectation, lenition of /s/ was much less widespread in this sample than previous accounts $[34,39]$. Moreover, /s/ sounds tended to be quite long, so the preference of this latter realisation could favour longer consonantal intervals when [s] is present, leading to more variation.

Table 1: Phonological characteristics of the samples

\begin{tabular}{rrrrrr}
\hline Participant & $\mathbf{1}$ & $\mathbf{2}$ & $\mathbf{3}$ & $\mathbf{4}$ & $\mathbf{5}$ \\
\hline Sequential vowels & 47 & 44 & 20 & 59 & 39 \\
Hiatus (\%) & 40.43 & 20.45 & 55.00 & 49.15 & 35.90 \\
Diphthong (\%) & 34.04 & 31.82 & 20.00 & 23.73 & 38.46 \\
Monophthong (\%) & 25.53 & 47.73 & 25.00 & 27.12 & 25.64 \\
\hline Voiced plosives & 65 & 46 & 45 & 67 & 31 \\
Stop (\%) & 43.08 & 45.65 & 46.67 & 35.82 & 22.58 \\
$\overline{\text { x duration }}$ & 0.046 & 0.084 & 0.056 & 0.055 & 0.045 \\
Spirant (\%) & 29.23 & 39.13 & 42.22 & 40.30 & 54.84 \\
$\overline{\text { x duration }}$ & 0.046 & 0.053 & 0.049 & 0.053 & 0.055 \\
Elided (\%) & 27.69 & 15.22 & 11.11 & 23.88 & 22.58 \\
\hline Stop (\%) & 85.83 & 95.00 & 93.06 & 87.39 & 90.67 \\
$\overline{\text { x duration }}$ & 0.065 & 0.070 & 0.080 & 0.065 & 0.071 \\
Spirant (\%) & 14.17 & 5.00 & 6.94 & 12.61 & 9.33 \\
$\bar{x}$ duration & 0.038 & 0.039 & 0.062 & 0.045 & 0.047 \\
\hline Voiceless Plosives & 103 & 76 & 67 & 104 & 68 \\
[s] (\%) & 64.71 & 70.77 & 57.14 & 86.41 & 74.0 \\
$\bar{x}$ duration & 0.092 & 0.077 & 0.109 & 0.071 & 0.087 \\
[h] (\%) & 23.53 & 26.15 & 38.10 & 7.77 & 10.0 \\
$\bar{x}$ duration & 0.053 & 0.680 & 0.062 & 0.058 & 0.034 \\
Elided (\%) & 11.76 & 3.08 & 4.76 & 5.83 & 16.00 \\
\hline /s/ realisations & 85 & 65 & 42 & 103 & 50 \\
\hline & & & & &
\end{tabular}

Table 2 shows the results obtained for rhythm metrics using two different methods. In general terms, it can be said that CLS has greater consonantal and vocalic variability than that which

Table 1: Results for rhythm metrics in this study.

\begin{tabular}{cccccccccccccc}
\hline Participant & Method & intV & intC & \multicolumn{2}{c}{ V\% } & \multicolumn{2}{c}{ VarcoV } & \multicolumn{3}{c}{ VarcoC } & \multicolumn{3}{c}{ nPVI-V } \\
\hline & 1 & 338 & 327 & 49.18 & $(1.54)$ & 75.05 & $(3.34)$ & 62.98 & $(2.54)$ & 57.29 & $(3.50)$ & 46.57 & $(3.00)$ \\
1 & 2 & 373 & 363 & 49.52 & $(1.45)$ & 73.16 & $(3.24)$ & 61.21 & $(2.35)$ & 55.08 & $(3.45)$ & 45.24 & $(2.81)$ \\
\hline & 1 & 259 & 250 & 50.64 & $(1.83)$ & 78.56 & $(3.96)$ & 52.01 & $(3.43)$ & 56.23 & $(4.38)$ & 46.26 & $(5.97)$ \\
2 & 2 & 297 & 280 & 51.45 & $(1.46)$ & 82.78 & $(3.54)$ & 46.17 & $(2.48)$ & 54.53 & $(3.24)$ & 41.76 & $(3.55)$ \\
\hline & 1 & 231 & 223 & 49.59 & $(1.74)$ & 70.02 & $(3.67)$ & 51.08 & $(3.22)$ & 55.40 & $(3.80)$ & 55.14 & $(4.42)$ \\
3 & 2 & 241 & 238 & 50.20 & $(1.68)$ & 78.21 & $(3.79)$ & 44.21 & $(2.97)$ & 57.20 & $(4.57)$ & 45.78 & $(3.65)$ \\
\hline & 1 & 351 & 369 & 47.31 & $(1.39)$ & 66.84 & $(2.79)$ & 64.07 & $(2.32)$ & 54.99 & $(2.80)$ & 52.86 & $(4.57)$ \\
4 & 2 & 393 & 398 & 49.89 & $(1.28)$ & 67.50 & $(2.59)$ & 54.68 & $(1.98)$ & 50.99 & $(2.46)$ & 43.47 & $(3.31)$ \\
\hline & 1 & 225 & 222 & 46.06 & $(1.75)$ & 74.89 & $(4.86)$ & 54.47 & $(2.78)$ & 51.01 & $(3.55)$ & 46.58 & $(4.50)$ \\
5 & 2 & 246 & 233 & 48.22 & $(1.32)$ & 71.62 & $(4.73)$ & 49.89 & $(3.05)$ & 46.42 & $(3.19)$ & 39.43 & $(4.80)$ \\
\hline
\end{tabular}


has been reported for other varieties of Spanish. However, there are differences between using one or the other method. V\% values in method one are lower than for two, which means that the former favoured the creation of consonantal intervals. Also, removing breathy and creaky portions led to shorter vowels and therefore a lower V\%. Similarly, the differences for VarcoC, (Figure 2), could be accounted for because of methodological choices. Placing onglides in the intervocalic interval would mean a higher number of consonants together which may give the impression of more complex clusters. Placing devoiced vowels as consonants might have also influenced to these results by favouring the creation of longer and more complex consonant intervals. Though the differences are not always huge (as is the case of P1), the tendency is for the metrics obtained with method one to be more 'extreme' than method two. It could be said that method one represents CLS as having more variability than it probably does. It is unclear which method is more faithful to the nature of speech timing in CLS.

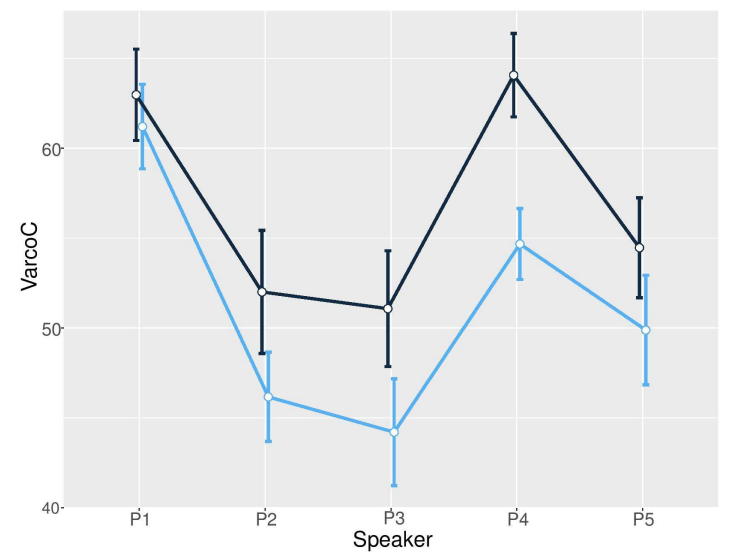

Figure 2: Comparison of VarcoC for the two methods, method one in black, method two in blue.

Figure 3 shows a comparison between this study of CLS and other varieties previously reported in the literature. At first sight, vocalic and consonantal variability in CLS is higher than most varieties in these studies for vocalic interval duration. Mexican Spanish was the only variety with higher nPVI-V and rPVI-C, which could be due to the variability in vowel length [26]. Also, there is a clear influence of methodology in these results. Mexican Spanish in [6] and the Castilian and Porteño samples in [17] are from spontaneous monologues, while the other data samples were elicited from read text. As seen in Figure 3, Mexican and Porteño Spanish are the closest to the samples in this experiment, pointing to the fact that spontaneous speech is clearly more variable than read speech. Nevertheless, the Castilian sample in [17] has lower nPVI-V and rPVI-C values than CLS, which reinforces the idea that this variety has more interval duration variation than PS.

\section{Discussion}

Regarding the first aim, characterising CLS in terms of the phonological processes, it can be said that speakers in this study favoured the production of diphthongs and monophthongs over hiatuses. There was also a tendency to realise voiced plosives as spirantised approximants, extending this approximation to voiceless stops. This alternation in the realisation of stops could potentially lead to consonant interval variability. In the case of s-lenition, this was not as extensive as expected for this variety, and the duration of [s] tokens was much longer than $[\mathrm{h}]$ tokens and even plosives. The presence of this allophone over lenited or elided forms, could also be a factor in the results reported for consonant interval durations. The results obtained from the rhythm metrics chosen for this analysis do reveal that this variety of Spanish has more consonantal and vocalic durational variation than other accounts in the literature. The phonological characteristics of CLS discussed here may influence the values obtained for rhythm metrics, but more research is needed to establish a connection. Knowing how other varieties behave could also shed some light on the relationship between phonological processes and timing.

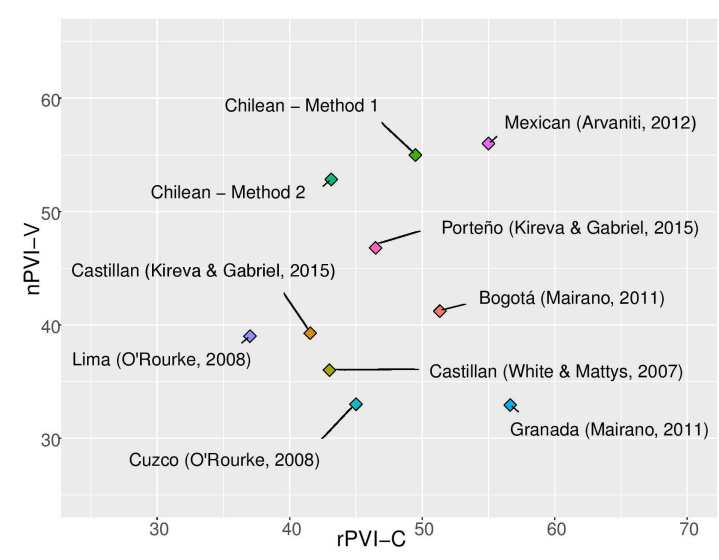

Figure 3: Average nPVI-V vs. rPVI-C for Chilean Spanish using two methods compared to other studies.

In the case of VarcoV, the results for CLS are quite close to the results obtained for English or Dutch in [15], or Porteño in [17]. In terms of nPVI-V, CLS shows more variability than PS and other LAS varieties, either revealing some level of vowel reduction or reflecting the anti-hiatic tendency of CLS, where diphthongs would be shorter than monophthongs. It appears to be close to most varieties of Spanish for rPVI-C and VarcoC. However, the results in this study varied depending on the method used. The more 'acoustic' approach of method one, that favours the creation of consonantal intervals, probably skews the results and favours more interval variability, suggesting that the language is more variable in terms of timing than it is. It is likely that method two is more faithful to CLS given that is favours the creation of CV sequences. Also, the task type used to elicit the data impacts the results given that spontaneous speech is more variable than read speech.

To conclude, this study offers a preview into the implementation of speech timing in CLS. It analysed some of the most noteworthy phonological phenomena of CLS, with the aim of establishing a link between these and the results obtained for vocalic and intervocalic variability as measured using rhythm metrics. This link is yet to be found and more data is needed to carry out statistical analyses to show a connection, if any. What is evident form this study is that CLS is more variable in terms of intervals, especially vocalic, than most varieties of Spanish. Also, being transparent about the methods used is essential, given that results may be altered by methodological choices. That said, transparency, together with an understanding of the phonology of CLS, can help understand what makes the "other" Spanish unique in terms of timing. 


\section{References}

[1] J. Fletcher, "The prosody of speech: Timing and rhythm," The handbook of phonetic sciences. New York: John Wiley \& Sons, 2010.

[2] S.A. Jun, "Prosodic typology: By prominence type, word prosody, and macro-rhythm," Prosodic typology II: The phonology of intonation and phrasing, pp. 520-539, 2014.

[3] A. Arvaniti, "The usefulness of metrics in the quantification of speech rhythm," Journal of Phonetics, vol. 40, no. 3, pp. 351-373, 2012.

[4] R. M. Dauer, "Stress-timing and syllable-timing re-analysed," Journal of Phonetics, vol. 11, pp. 51-62, 1983.

[5] E. Grabe, and E.L. Low, "Durational Variability in Speech and the Rhythm Class Hypothesis," in Papers in Laboratory Phonology. Berlin: Mouton de Gruyter, 2002.

[6] A. Arvaniti, "Rhythm, timing and the timing of rhythm," in Phonetica, vol. 66, no. 1-2, pp. 46-63, 2009.

[7] F. Ramus, M. Nespor, and J. Mehler, "Correlates of linguistic rhythm in the speech signal," in Cognition, vol. 72, pp. 1-28, 1999

[8] V. Dellwo, "Rhythm and Speech Rate: A Variation Coefficient for deltaC," Language and language-processing. Frankfurt/Main: Peter Lang, 2006.

[9] P. Prieto, M. del Mar Vanrell, L. Astruc, E. Payne, and B. Post, "Phonotactic and phrasal properties of speech rhythm. Evidence from Catalan, English, and Spanish," Speech Communication, vol. 54 , no. 6 , pp. $681-702,2012$

[10] L. Wiget, L. White, B. Schuppler, I. Grenon, O. Rauch, and S. L. Mattys, "How stable are acoustic metrics of contrastive speech rhythm?" Journal of the Acoustical Society of America, vol. 127, pp. 1559-1569, 2010

[11] G.E. Peterson, and I. Lehiste, "Duration of syllable nuclei in English" the Journal of the Acoustical Society of America, vol. 32, no. 6, pp. 693-703, 1960.

[12] S. Frota and M. Vigário, "On the correlates of rhythmic distinctions: The European/Brazilian Portuguese case," Probus, vol. 13 , no. 2 , pp. $247-275,2001$.

[13] E. O'Rourke, "Speech rhythm variation in dialects of Spanish: applying the pairwise variability index and variation coefficients to Peruvian Spanish," in Proc. Fourth Conf. on Speech Prosody, 2008: Citeseer, pp. 431-434.

[14] L. J. van Maastricht, "Second Language Prosody: Intonation and rhythm in production and perception," Tilburg University, 2018.

[15] L. White, and S.L. Mattys, "Calibrating rhythm: First language and second language studies" Journal of Phonetics, vol. 35, no. 4 pp. 501-522, 2007.

[16] P. M. Carter, "Quantifying rhythmic differences between Spanish, English, and Hispanic English," Amsterdam Studies in the Theory and History of Linguistic Science Series 4, vol. 272, p. 63, 2005.

[17] E. Kireva and C. Gabriel, "Rhythmic properties of a contact variety: Comparing read and semi-spontaneous speech in Argentinean Porteño Spanish," in Prosody and Language in Contact: Springer, 2015, pp. 149-168.

[18] J. I. Hualde, "Patterns in the lexicon: Hiatus with unstressed high vowels in Spanish," Advances in Hispanic linguistics, vol. 1, pp. 182-198, 1999.

[19] P. Mairano, "Rhythm typology: Acoustic and perceptive studies" Doctoral Thesis, University of Turin, Italy, 2011.

[20] A. Turk, S. Nakai, and M. Sugahara, "Acoustic segment durations in prosodic research: A practical guide" Methods in empirical prosody research, vol. 3, pp. 1-28, 2006.

[21] K. L. Pike, The Intonation of American English. Michigan: University Press, 1945.

[22] D. Abercrombie, Elements of general phonetics. Edinburgh University Press Edinburgh, 1967.

[23] M. Á. Quesada Pacheco, El Español de América. Cartago: Editorial Tecnológica de Costa Rica, 2002.

[24] J. M. Lipski, "Socio-phonological variation in Latin American Spanish," in The handbook of Hispanic sociolinguistics. Malden, MA: Wiley-Blackwell, 2012, pp. 72-97.
[25] J. I. Hualde, "Stress and rhythm," in The handbook of Hispanic linguistics. Malden, MA: Wiley-Blackwell, 2012, pp. 153-172

[26] J. M. Lope Blanch, "En torno a las vocales caedizas del español mexicano," Nueva revista de filología hispánica, vol. 17, no. 1/2, pp. $1-19,1963$.

[27] M. Alba, "Accounting for variability in the production of Spanish vowel sequences," in Selected proceedings of the 9th Hispanic Linguistics Symposium, 2006: Somerville, MA: Cascadilla Proceedings Project, pp. 273-285.

[28] L. F. Baron Birchenall, "Influence of sentence-level rhythmic regularity and phonological phrasing on linguistic accommodation during conversational interactions: the case of Spanish speaking dyads," Aix-Marseille, 2018.

[29] C. S. Salcedo, "The phonological system of Spanish," Revista de lingüistica y lenguas aplicadas, vol. 5, pp. 195-209, 2010.

[30] J. I. Hualde, M. Simonet, and M. Nadeu, "Consonant lenition and phonological recategorization," Laboratory Phonology, vol. 2, no. 2, pp. 301-329, 2011

[31] V. Dellwo, A. Fourcin, and E. Abberton, "Rhythmical classification of languages based on voice parameters," Proceedings of ICPhS XVI, pp. 1129-1132, 2007.

[32] M. A. Figueroa Candia, "Lenition in the production and perception of Chilean Spanish approximant consonants: Implications for lexical access models," UCL (University College London), 2016.

[33] K. E. Borland Delorme, "La variación y distribución alofónica en el habla culta de Santiago de Chile," Onomázein, no. 10, pp. 103 $115,2004$.

[34] K. Broś, "La aspiración y la pérdida de/s/en el español de Chile como ejemplo de opacidad," Onomázein, no. 28, pp. 56-71, 2013.

[35] S. Sadowsky, "Variación sociofonética de las consonantes del castellano chileno," Sociolinguistic studies, vol. 9, no. 1, pp. 7192, 2015.

[36] S. M. Sadowsky, "Naturaleza fonética y estratificación sociolingüística de los alófonos vocálicos del castellano de Concepción (Chile)," Universidad de Concepción, 2012.

[37] S. Sadowsky, H. Painequeo, G. Salamanca, and H. Avelino, "Mapudungun," Journal of the International Phonetic Association, vol. 43, no. 1, pp. 87-96, 2013.

[38] D. Román, C. Quezada, and L. Aguilera, "Duración de vocales idénticas en límite de palabras en español de Chile," Estudios de fonética experimental, vol. 27, pp. 151-172, 2018.

[39] K. Miller and C. Schmitt, "Effects of variable input in the acquisition of plural in two dialects of Spanish," Lingua, vol. 120, no. 5, pp. 1178-1193, 2010.

[40] R. Baker and V. Hazan, "DiapixUK: task materials for the elicitation of multiple spontaneous speech dialogs," Behavior research methods, vol. 43, no. 3, pp. 761-770, 2011.

[41] T. Kisler, U. Reichel, and F. Schiel, "Multilingual processing of speech via web services," Computer Speech \& Language, vol. 45, pp. 326-347, 2017.

[42] P. Boersma and D. Weenink, "Praat: doing phonetics by computer [Computer program]," version 6.1.06, 2018.

[43] P. Machač and R. Skarnitzl, Principles of phonetic segmentation. Prague: Epocha Publishing House, 2009.

[44] L. Aguilar, "Hiatus and diphthong: Acoustic cues and speech situation differences," Speech communication, vol. 28, no. 1, pp. 57-74, 1999.

[45] J. I. Hualde and M. Prieto, "On the diphthong/hiatus contrast in Spanish: some experimental results," Linguistics, vol. 40, no. 2; ISSU 378, pp. 217-234, 2002

[46] J. M. Smith, T. L. Flores, and M. S. Gradoville, "An analysis of vowels across word boundaries in Veracruz, Mexican Spanish," IULC Working Papers, vol. 8, no. 1, 2008.

[47] M. Gordon and P. Ladefoged, "Phonation types: a cross-linguistic overview," Journal of phonetics, vol. 29, no. 4, pp. 383-406, 2001.

[48] P. Mairano and A. Romano, "Un confronto tra diverse metriche ritmiche usando Correlatore 1.0," La dimensione temporale del parlato, vol. 427, p. 44, 2010. 


\section{University Library}

\section{- M M I N E R VA A gateway to Melbourne's research publications}

Minerva Access is the Institutional Repository of The University of Melbourne

Author/s:

Reynolds, I;Maxwell, O;Wigglesworth, G

Title:

The "other" Spanish: Methodological issues in the study of speech timing in Chilean Spanish

Date:

2020-01-01

Citation:

Reynolds, I., Maxwell, O. \& Wigglesworth, G. (2020). The "other" Spanish: Methodological issues in the study of speech timing in Chilean Spanish. Proceedings of the 10th

International Conference on Speech Prosody, 2020-May, pp.576-580. International Speech Communication Association (ISCA). https://doi.org/10.21437/SpeechProsody.2020-118.

Persistent Link:

http://hdl.handle.net/11343/268021 